\title{
JUVENTUDE E AUSTERIDADE: IMPLICAÇÕES PARA ALÉM DO MUNDO DO TRABALHO
}

\author{
Youth and Austerity: Implications Beyond the World of Work
}

\author{
Lays Bárbara Vieira Morais'
}

\begin{abstract}
Resumo
O presente texto se configura como um exercício teórico, ensaístico, de especulação com base em estudos referentes aos efeitos da austeridade, seja quanto a sua característica redução de gastos em serviços públicos, ou quanto ao seu desenrolar político-ideológico-social. Por conta da condição recente desse fenômeno no Brasil, não podemos inferir com certeza absoluta que nossas proposições de fato se realizarão, mas, tendo como base estudos originados em contextos onde a austeridade está "mais desenvolvida", propõem-se aqui a apresentação de um provável efeito futuro que veremos se desenvolver ao longo dos anos de austeridade que se seguirão, em especial na população jovem brasileira. Defendese que a atual crise fiscal, e suas políticas de austeridade, possuem uma origem estrutural, e não de gestão, devido em grande parte as contradições insuperáveis entre democracia e capitalismo, e que essas contradições afetam a construção e o desenvolvimento da subjetividade dos sujeitos. Buscou-se deixar claro o caráter ideológico e de classe desse fenômeno e que a forma com que um Estado conforma a sua tributação deve ser uma decisão de cunho democrático. Porém, com a erosão na base de arrecadação dos Estados nacionais ocorrida nos últimos anos, vem-se transformando cada vez mais negativamente essa lógica.
\end{abstract}

Palavras-chave: austeridade, capitalismo, democracia, jovens, subjetividade.

\begin{abstract}
The present text is a theoretical and essayistic exercise of speculation based on studies concerning the effects of austerity, whether in terms of its characteristic reduction of public services expenditures or its political-ideological-social evolution. Because of the recent condition of this phenomenon in Brazil, we can not infer with absolute certainty that our propositions will indeed be realized, but, based on studies originated in contexts where austerity is "more developed", we propose here the presentation of a Probable future effect that we will see develop over the years of austerity that will follow, especially in the young Brazilian population. It is argued that the current fiscal crisis, and its austerity policies, have a structural rather than a management origin, largely due to the insurmountable contradictions between democracy and capitalism, and that these contradictions affect the construction and development of the subjectivity of Subjects. It was sought to make clear the ideological and class character of this phenomenon and that the way in which a State conforms to its taxation must be a decision of a democratic nature. However, with the erosion of the base of collection of the national States occurred in recent years, this logic is becoming more negative.
\end{abstract}

Keywords: austerity, capitalism, democracy, youth, subjectivity.

\footnotetext{
${ }^{1}$ Mestre em Sociologia pelo Programa de Pós-Graduação em Sociologia da Universidade Federal do Goiás (PPGS/FCS/UFG) e mestranda em Ciência Política pelo Programa de Pós-Graduação em Ciência Política da Universidade Federal do Goiás (PPGCP/FCS/UFG). Email: lahbvm@gmail.com
} 


\section{Introdução}

Nos últimos anos, os efeitos e a presença da austeridade em solo brasileiro estão cada vez mais presentes e explicitas para nós cidadãos, exemplificadas principalmente pela PEC 55, a chamada PEC dos gastos públicos, a reforma da Previdência e a reforma trabalhista. A primeira dessas medidas se refere a imposição de um limite de gastos ao governo por um período de 20 anos, medida jamais vista na história mundial e que será melhor destrinchada no decorrer do texto. Já a reforma da Previdência possui como pontos principais: a idade mínima para requerer aposentadoria passa a ser 65 anos para homens e 62 anos para mulheres, eleva o tempo mínimo de contribuição de 15 anos para 25 anos, para conseguir a aposentadoria integral será preciso contribuir por um período de 40 anos e haverá regras distintas para os trabalhadores. E por fim, a reforma trabalhista visa, dentre outras coisas, que patrões e empregados podem promover acordos independentemente do que prevê a lei trabalhista. O trabalhador que entra com ação contra empresa fica responsabilizado pelo pagamento dos honorários caso perca a ação, e não mais os custos são cobertos pelo Ministério Público, como é atualmente. Por fim, a proposta aprovada pelo governo cria duas modalidades de contratação: trabalho intermitente, por jornada ou hora de serviço, e o home office.

Os aspectos econômicos de tais medidas, assim como seus aspectos políticos, fundamentalmente no que se refere ao exercício da democracia, já foram e ainda são amplamente discutidos ${ }^{2}$, assim sendo, não serão o nosso foco neste texto. Também deve ficar claro que não é nosso intuito dar como encerrada as discussões sobre o tema, mas apenas apontar lacunas a serem preenchidas e caminhos alternativos possiveis.

Portanto, inicialmente apresentaremos questões gerais sobre a origem e desenvolvimento da crise financeira que se acomoda mundialmente desde 2008, para satisfazer o entendimento no que tange ao contexto no qual a problemática aqui abordada está inserida. Passando para uma relação mais especifica entre as finanças dos Estados e a sua dinâmica democrática e, por

2 A título de exemplo: https://www.youtube.com/watch?v=BRX_9sr6Yis e https: / / www.youtube.com/watch?v=5TtScvPCirU. 
fim, tentaremos abordar os efeitos desse fenômeno em uma parcela especifica da população, o jovem. Este sim constitui o foco do presente texto. E, para tal empreitada, usaremos como exemplo o Brasil, onde a questão da austeridade ainda é recente e pouco estudada.

\section{Sobre crises econômicas}

Já é de conhecimento do senso comum que a "explosão" da bolha imobiliária norte-americana em 2008 acabou por tomar dimensões globais, tendo em vista o sistema "integrado" do capitalismo democrático neoliberal em que estamos inseridos. O que muitos não sabem é que essa configuração político-econômica das sociedades ditas avanças, esconde um problema estrutural. Segundo Streeck (2012), a crise atual só pode ser plenamente entendida à luz das transformações continuas e inerentemente conflituosas do que chamamos de "capitalismo democrático".

Para Streeck (2012), essa formação social se estabeleceu completamente apenas após a Segunda Guerra Mundial e mais notadamente em países do norte global. Essa conformação seria caracterizada por diversas crises e um permanente conflito entre mercados capitalistas e políticas democráticas, onde tal conflito recrudesceu com o término do período de expansão econômica e a reversão das altas taxas de crescimento ocorridas entre os anos de 1950 e 1973. Nesse período, a ideia amplamente difundida era que para que a democracia e o capitalismo fossem compativeis, o segundo deveria ser submetido a um controle político amplo para proteger a primeira das restrições impostas pelo livre mercado. Entretanto, não demorou muito para surgir teorias defendendo que o mais adequado é deixar os mercados livres da interferência política, a exemplo das teorias da escolha pública.

Como lembra Streeck "suspeitas de que capitalismo e democracia possam não se combinar facilmente estão longe de ser novidade" (2012, p. 36), visto que remetem aos temores da burguesia e da direita política, presente no século XIX e no decorrer de boa parte do século XX, em relação a chamada "regra da maioria", na qual o entendimento era o de que o "predomínio dos pobres sobre os ricos, acabaria por extinguir a propriedade privada e os mercados livres" (STREECK, 2012, p. 36). Assim, segundo Wood (2011) a 
democracia acaba tornando-se um mecanismo econômico e o mercado capitalista constituindo-se, ao mesmo tempo, como espaço político e econômico, um terreno caracterizado por relações de dominação e coação. Na atual conjuntura política e econômica (mercado competitivo, desregulamentado e/ou flexibilizado), um capitalismo que seja humano, social ou verdadeiramente democrático e igualitário seria mais irreal e utópico do que qualquer ideia sobre socialismo.

Para explicar esse atrito, Streeck (2012) caracteriza o capitalismo democrático em dois regimes conflitantes de alocação de recursos: um que opera quanto ao chamado "livre jogo das forças de mercado" e o outro que se baseia em necessidades ou direitos sociais. Teoricamente, sob essa forma de capitalismo, os governos devem cumprir ambos simultaneamente. Mas na prática, acabam negligenciando um pelo outro. Mais especificamente, com a expansão do neoliberalismo, da flexibilização, instabilidade e lógicas de mercado, o segundo tende a perder espaço para o primeiro. Passa-se a difundir uma ideia de que a verdadeira justiça é aquela promovida pelo mercado e/ou equiparam os interesses de mercado com o interesse geral. Assim, com a crise do chamado Estado de Bem-Estar social ${ }^{3}$, e a necessidade de fortes diretrizes desinflacionarias acompanhada da queda da sindicalização, a era neoliberal teve início e trouxe consigo o abandono, por vários governos, das lições do capitalismo democrático do pós-guerra. Que, por sua vez, sustentava que o desemprego solaparia o apoio político (KALECKI, 1943), não apenas ao governo da vez, mas também ao próprio capitalismo democrático (STREECK, 2012).

Nesse período, à medida que a inflação recuou, a dívida pública, por outro lado, cresceu, muito por conta da relação demanda dos cidadãos/recursos do governo. Daí que a estagnação do crescimento impôs mais do que nunca aos contribuintes à tributação, mesmo em um cenário de crescente desemprego. Acrescenta-se a isso que, segundo Streeck, os vários direitos sociais criados nesses países nos anos de 1970 começaram a ser

\footnotetext{
3 Vale ressaltar que o fenômeno do "Estado de Bem-Estar social" não ocorreu em todos os países do mundo, a exemplo da América Latina, mas entender suas consequências é importante para compreender a atual dinâmica econômica mundial, que tem como base um mercado globalizado.
} 
cobrados, onerando cada vez mais as finanças públicas e com uma inflação não mais disponível para estreitar essa lacuna.

Em vez de inflacionar a moeda corrente, os governos começaram a
tomar empréstimos em proporções crescentes para atender demandas
de beneficios e serviços como um direito dos cidadãos, assim como
exigências concorrentes de que a renda refletisse o juízo de mercado e
desse modo contribuísse para maximizar o uso lucrativo dos recursos
produtivos (STREECK, 2012, p. 45).

Entretanto, assim como a inflação, esse acumulo de divida pública não pode perdurar eternamente, até por que o déficit público acaba por ter um efeito de esvaziamento sobre os investimentos privados, a exemplo do caso norte-americano apresentado pelo autor. Para "pacificar" uma economia nesse estado, diversas medidas podem ser tomadas, a mais usual delas são as politicas de austeridade, que envolvem profundos cortes em gastos públicos e mudanças nas politicas sociais. No caso norte-americano essas medidas acabaram gerando o chamado "keynesianismo privado" (STREECK, 2012) e os ricos foram poupados de aumentos de impostos, como normalmente costuma acontecer nos países em que os governos se comprometem com uma austeridade permanente, muito por conta do seu aspecto político-ideológico (o qual abordaremos mais detidamente posteriormente).

Mas em 2008, a já antiga crise do capitalismo democrático do pósguerra entrou em sua fase mais recente. O poder político dos Estados foi convocado novamente para colocar à disposição recursos futuros a fim de assegurar a paz social, assumindo assim a responsabilidade por uma grande parcela da atual divida que foi originalmente gerada no setor privado, no intuito de tranquilizar os credores. Ainda de acordo com o autor, mesmo com uma crise global e longe do fim, começaram a exigir o retorno do equilíbrio fiscal via medidas de austeridade, principalmente para assegurar seus investimentos na divida pública, mas isso acabou por resultar em um conflito distributivo entre investidores financeiros globais e Estados-nação, que devem agora forçar garganta a baixo de seus cidadãos cortes de gastos sem precedentes (STREECK, 2012). Ou seja, quem irá pagar a conta da estabilização financeira é o cidadão comum e não os detentores do dinheiro real, os grandes bancos nacionais e internacionais, mediante cortes em benefícios e serviços públicos e aumento de impostos. 


\section{Austeridade e democracia: a relação entre questão fiscal e dinâmica democrática}

Para darmos início as nossas inferências, devemos tentar entender, partindo do Estado capitalista moderno, a relação entre um estado, a democracia, os tributos e a própria austeridade, para assim apreender a influência dessa dinâmica nas nossas vidas e as consequências disso.

Schumpeter (1991), autor bastante conhecido pelos seus escritos referentes ao elitismo político, por outro lado costuma ser desconhecido no que tange os seus escritos sobre teoria de Estado e Sociologia fiscal. Em seu texto "The crisis of the tax state", ele já inicia sua discussão afirmando a impossibilidade de perduração histórica do capitalismo, e prossegue tentando demonstrar o porquê deste fato. Segundo ele, o liberalismo não é uma teoria do estado mínimo, ele se configura muito mais como um aparato de impostos e maquinário voltados para objetivos de arrecadação. Com essa dinâmica, Schumpeter chama a atenção para a diferenciação existente entre um imposto pago por particulares para algo que se ache comum de imposições de taxas para algo que se pretende comum. Daí um problema que menos se baseia nos interesses que esses impostos vão atender e mais no fato de se criar uma espécie de "fundo ontológico" público de recursos. Assim, conflitos irão surgir para ver quem irá gerar esse fundo (a aristocracia, o povo, o príncipe, etc.) e também uma burocracia estatal será erigida.

Vale ressaltar que é apenas no estado moderno que ocorre a separação entre o político e o econômico (WOOD, 2012), onde o político diz respeito ao que é público e o econômico se volta para o que é privado. Na teoria de Estado schumpeteriana, com base em uma sociologia fiscal, os Estados modernos (Estados fiscais) irão surgir não apenas a partir de crises do feudalismo, mas também dessa separação entre "imperium" e "dominium"4, as quais as politicas fiscais serão uma delas, assim como serão semeadoras de cultura. Para Schumpeter, o Estado moderno (ou fiscal) surge como uma resposta à crise medieval, onde o modo feudal de se relacionar não tinha mais lugar e não havia soberania, apenas existia uma justaposição de leis, direitos, etc. Agora,

\footnotetext{
4 Onde o primeiro conceito corresponde a propriedade privada e o segundo se refere a um direito de comando vinculado a certos magistrados civis e, eventualmente, ao imperador, pode ser entendido também como Estado, como apontado por Wood (2012). Essa autora defende que com o advento do capitalismo, propriedade e poder político, dominium e imperium, tornaram-se estruturalmente desencaminhados de maneira historicamente sem precedentes.
} 
com um novo modelo que separa o político e o econômico, em que o Estado encontra sua forma de dominação especifica, havia solo até mesmo para se democratizar estados, pois com essa mudança a soberania estava posta, o poder passou a estar em algo físico (como o parlamento). Nesse sentido:

The concept of the state is inapplicable to the circumstances then existing, but not in the sense that what we see today within the sphere of the state was absent and that only the private sphere remained; instead, the organizational forms of that time combined both what we nowadays call the public and the private sphere in one essentially different unity (Schumpeter, 1991, p. 104) ${ }^{5}$.

Ou seja, a separação entre econômico e político não é indissolúvel e nem absoluta (leituras assim levariam a um determinismo econômico), mas, o modo como a dinâmica tributaria acontece, acaba por determinar em grande medida uma dada realidade social. É a obrigação tributária que define o capitalismo atual. Assim, Schumpeter nos mostra que a questão orçamentaria é central para os estados e parte fundamental nas crises fiscais que os atingem. E, apesar do capitalismo ter se desenvolvido de forma diferente nos países ditos de "primeiro mundo", aqueles estudados por Schumpeter e Wood, em comparação aos chamados países de "terceiro mundo", a ideia de que a tributação é um pressuposto lógico do estado e da manutenção do capitalismo se mantem.

Logo, o contexto atualmente atravessado pelos Estados capitalistas, segundo o qual sua manutenção material é crescentemente ameaçada pelos agentes econômicos, sempre buscando vantagens, especialmente fiscais, se trata de uma manifestação última da tensão entre a política democrática e o modo de produção capitalista, os quais, mesmo tendo se harmonizado, ao menos provisoriamente após a Segunda Guerra Mundial, encerram relevantes, senão insuperáveis, contradições entre si (TAVARES, 2008).

Porém, a ideia de um Estado mínimo, defendida pelas correntes liberais, e que ascendeu principalmente com o neoliberalismo e sua proposta de combater a crise do Estado de Bem-Estar social, nos países de capitalismo

\footnotetext{
5 Em tradução livre: "O conceito do estado é inaplicável às circunstâncias que existem, mas não no sentido de que o que vemos hoje na esfera do estado estava ausente e que apenas a esfera privada permaneceu; Em vez disso, as formas organizacionais desse tempo combinaram o que hoje chamamos de esfera pública e privada em uma unidade essencialmente diferente".
} 
avançado, vem demonstrando historicamente também não ser a solução ${ }^{6}$. Pensemos, ainda com base em Schumpeter (1991): para que haja a ideia de indivíduo (ponto fundamental do liberalismo e neoliberalismo) é necessário que haja a ideia de um bem comum, uma sociedade onde haja um interesse comum (como já haviamos mencionado acima); para suprir as necessidade desse bem comum, é preciso que esse Estado promova a arrecadação fiscal, mas levada ao seu extremo, essa arrecadação pode prejudicar suas próprias bases, o problema estrutural na tributação de um Estado fica visivel, já que tributar demais no intuito de sanar sua divida pública, por exemplo, gera competição fiscal, queda nos investimentos e insatisfação popular.

A questão fiscal, e a atual crise econômica, não podem ser entendidas satisfatoriamente tendo em vista apenas seus aspectos econômicos. As medidas de austeridade estão recheadas não só de economia, mas também de muita politica. O’Connor (1977), por exemplo, advoga que as finanças tributárias, em qualquer época, são formas de exploração econômica e, portanto, um problema que requer analise de classe. Entretanto, os Estados necessitam criar constantemente formas tributárias equitativas para esconder o conteúdo não equitativo da estrutura tributária e a natureza exploradora da estrutura classista. Corroborando essa ideia, Offe e Ronge (1984) afirmam que as determinações funcionais do Estado são a privatização da produção, dependência dos impostos, acumulação como ponto de referência e a legitimação democrática, esta última sendo usada para encobrir o fato de que os recursos materiais, que permite o efetivo poder estatal, dependem dos ingressos extraídos do processo de acumulação, compondo uma dominação estrutural.

As classes dominantes costumam tentar esconder ou justificar e racionalizar ideologicamente a exploração tributária, por meio de novos slogans ${ }^{7}$. Uma outra forma de exemplificar, segundo O’Connor (1977), é com o fato de que ainda hoje as taxas de importação conservam-se como modelos

\footnotetext{
6 A proposta desse texto não é apresentar uma outra solução ao problema da recessão causada pela crise fiscal atual, mas sim reforçar o fato de que as medidas de austeridade não são de fato o "remédio", e iremos embasar isso as consequências negativas, no que tange a esfera política, em uma parcela específica da população.

7 No caso brasileiro, após Michel Temer assumir o governo, o slogan passo de "Brasil, pátria educadora" para "Ordem e progresso".
} 
tributários dos países chamados subdesenvolvidos, exatamente por serem de fácil dissimulação. Ainda de acordo com esse pensador, a exploração tributária é também dissimulada nos países do norte global e os impostos indiretos, mediante vendas e consumo, continuam a ser fontes importantes das receitas estaduais e locais. O foco de O'Connor é também o cenário dos Estados Unidos, mas as considerações inferidas por ele também podem ser pensadas para diversas outras localidades do mundo.

Para o referido autor, a justificativa para a exploração estaria baseada nas ideias de: incentivo, onde a ideologia tributaria oficial defende que os tributos não devem diminuir os incentivos, quer da oferta de capital quer do dinheiro a investir; e, por fim, a capacidade de pagamento e o tratamento igualitário, que sustentam que cada membro da sociedade deve pagar impostos de forma correspondente a sua renda pessoal, porém o uso da renda, e não o da riqueza, como medida da capacidade de pagamento é gritantemente discriminatória frente os trabalhadores em favor do grande capital. Em resumo, a sociedade capitalista não é uma sociedade igualitária, assim um sistema fiscal que se proponha tratar seus membros de modo igual vai apenas reforçar as desigualdades existentes.

$\mathrm{Na}$ maior parte das sociedades capitalistas, existe a aparência de que a classe burguesa é tributada de vários modos, mas na realidade, a maior parte dos impostos sobre a renda e as folhas de pagamento das empresas acabam sendo transferidos e absorvidos pelos trabalhadores e consumidores e não pelos proprietários das empresas tributadas. Abordando historicamente o imposto de renda para aludir o caráter de classe da tributação nos Estados Unidos, O’Connor afirma:

[...] há conexão intima entre o desenvolvimento do imposto de renda das empresas e o imposto de renda individual. O primeiro imposto de renda individual (1913) isentou a grande maioria dos trabalhadores e só se aplicou aos ricos. Os capitalistas responderam à ameaça do primeiro tributo de classe da América (primeiro, de vida curta e última) fazendo campanha pelo tributo sobre a renda empresarial, como um substituto do imposto de renda individual (O'CONNOR, 1977, p. 207).

Esses impostos, referentes a vendas, consumo, previdência social e de renda individual são espoliativos. As cobranças referentes a previdência, por exemplo, acabam recaindo principalmente sobre trabalhadores que são mal remunerados por conta de sua taxa única que não leva em consideração o 
nivel de renda, isso muito por que uma das características do sistema tributário no Brasil é o seu caráter regressista8.

Assim, para resumir, e como já demonstrado, o sistema tributário cumpre duas funções: primeiro, permite que o capital monopolista aumente seus ganhos e bens, com isso exercendo importante papel no fortalecimento da classe dominante; e segundo, é usado para cobrir os custos das despesas de capital de caráter social e das despesas correntes de cunho social, onde o sistema toma recursos das pequenas empresas e da classe trabalhadora, forçando os trabalhadores a continuarem a ser trabalhadores (O'CONNOR, 1977). O Estado, que se apresenta como mediador e representante universal da sociedade, acaba não o sendo e se ancorando na acumulação capitalista (OFFE; RONGE, 1984). A austeridade pode até fazer sentido intuitivamente, mas em essência ela acaba sendo um dogma ideológico, com pouca adesão a realidade, que serve a um projeto de classe e que é perigosa do ponto de vista social e econômico (BLYTH, 2013).

Obviamente isso terá reflexos políticos, como já foi apontado brevemente em vários momentos desse texto, principalmente no que tange a legitimidade. A capacidade de gestão política do capitalismo democrático declinou abrangentemente no atual sistema político-econômico global, tanto no norte como no sul global. Segundo Streeck (2012), com o advento de uma nova fase de austeridade, a capacidade do Estados-nação de fazer a mediação entre os direitos do cidadão e os requisitos de acumulação do capital foram severamente afetados, precarizou-se. As crises e as contradições do capitalismo democrático se tornaram definitivamente internacionalizadas e os governos agentes de organizações internacionais, causando toda sorte de desarranjos políticos, tais como diminuição do comparecimento às urnas,

\footnotetext{
8 Dados interessantes sobre esse assunto, referentes a 2010-1014, tais como o fato da a tributação total das empresas varia de $16,33 \%$ a $19,53 \%$ do faturamento no regime de lucro presumido, ou de $4,5 \%$ a $16,85 \%$ se estiver no regime simples (nos países da OCDE, a média de tributação total sobre o lucro atinge $43,1 \%$ ). Isso acaba incentivando a terceirização. Outro dado esclarecedor é que a tributação sobre bens alimentícios no Brasil, a carga sobre bens e serviços responde por 15,7\% do total arrecadado, ante $10,9 \%$ na média da OCDE e 10,7\% no México - a segunda maior economia da América Latina. Diante da regressividade da carga tributária brasileira, as mulheres negras tornam-se o setor da sociedade mais atingido por esse sistema, justamente porque elas se concentram nos extratos de menor renda da população. Podem ser encontrados em:

http: / /www.ipea.gov.br/desafios /index.php?option=com_content\&view=article\&id=3233\&catid=30\&It emid $=41$.
} 
distúrbios nas ruas, ascensão de partidos populistas e/ou conservadores, etc. Por exemplo, especificamente no que diz respeito à diminuição do comparecimento às urnas, Schafer e Streeck (2013) afirmam que entre a população baixa educação formal e entre os desempregados, o índice de não comparecimento é significativamente maior em períodos de crise fiscal. Essas tensões e contradições estruturais, essa sucessão de crises do capitalismo democrático desde os anos de 1970, fazem com que agora, mais do que nunca, o poder econômico pareça ter se tornando poder político, dando fim a aparente separação entre econômico e político feita na ascensão do Estado moderno, como apontou Wood (2012).

Schafer e Streeck (2013) afirmam que o crescimento da dívida pública, o aumento das taxas de juros e a maturação do Estado social, principalmente em países da OCDE, vem ameaçando a democracia, tendo em vista a decrescente margem de decisão permitida pelas margens fiscais dos Estados. A crise seria um desdobramento inevitável da contradição irreconciliável entre política democrática e economia de mercado, sendo que a estabilidade e a restrita prosperidade é que deve ser explicada e entendida como restrita ao chamado "Norte Global". A crise é apenas a face atual de um processo histórico continuo, como demonstrado por Schumpeter (1991) e indica a virada dos estados democráticos em favor de oligarquias financeiras. Streeck (2012), cita como exemplo que em países como a Grécia e a Irlanda, qualquer coisa semelhante a democracia será efetivamente suspensa por muitos anos, pois, para proceder "responsavelmente" aos moldes dos mercados e instituições internacionais, os governos nacionais precisam impor uma rígida austeridade, a preço de serem cada vez mais irresponsáveis frente a seus cidadãos. Segundo teóricos como Crouch (2004), vivemos agora em uma "pósdemocracia".

Para Crouch (2004), democracia está ligada a possibilidade de as pessoas influenciarem e participarem das tomadas de decisões, mediante um tratamento igualitário. Entretanto, as reformas econômicas, fiscais, jurídicas e políticas dos últimos anos têm afastado cada vez mais a realidade social e política dessa ideia de democracia. O Estado atualmente se configura como um Estado fiscal, não apenas em termos simbólicos, mas concretamente 
também. Ele vem se tornando cada vez mais uma supermáquina de arrecadação e que, por outro lado, já se mostra engessada. Por isso, discutir orçamento é discutir democracia (a coletividade discutir os rumos do orçamento). Formalmente, nunca ouve tantos países ditos democráticos no mundo, mas será que as pessoas realmente estão influenciando as decisões politicas? Ainda mais em uma era de intensificação da austeridade e da, cada vez mais explicita, tirada de dinheiro do trabalho para o capital.

A de se ressaltar que, esses ideais de participação, influência e igualdade nunca ocorreram de fato nas democracias existentes, talvez o mais próximo disso que o ocidente chegou foram os regimes de socialdemocracia. Entretanto, votar em um partido, ou plano de governo, de direita ou de esquerda ainda fazia alguma diferença empírica. Porém, esse movimento, muito por conta da crise econômica iniciada em 2008 e sua posterior austeridade, vem acabando.

Segundo Crouch (2004), mesmo alguns afirmando que as pessoas estão mais criticas e exigentes, e os Estados mais transparentes, isso não basta. Atualmente, o lobby empresarial nunca foi tão grande, a sociedade é uma sociedade da vigilância, a política do desanimo (ou o ativismo negativo quando as pessoas se desinteressam pela politica e, por exemplo, deixam de comparecer às urnas ${ }^{9}$ ) e a ideia de transparência dos governos pode não perdurar. Tudo isso não significa mais democracia, e sim o contrário.

O Estado ainda governa, pelo menos teoricamente, mas não será assim por muito tempo na visão de Crouch, pois ele foi de vez sequestrado pela burguesia financeira. Vivemos então agora em uma ditadura? Não, para o autor estamos no que ele chama de "pós-democracia”, seus elementos oficiais estão ali (ainda votamos, por exemplo), mas o que de fato lhe dá significado se dissipa (nosso voto não diz nada, não determina quem realmente governa), pois a instancia das decisões públicas tem se deslocado cada vez mais dos governos soberanos para o mercado.

\section{PEC 55: a austeridade corporificada no Brasil}

Os aspectos estruturais da tributação se repetem em diversas localidades, assim como os problemas advindos deles. A austeridade, por

\footnotetext{
9 Mas as grandes corporações continuam bastante interessadas no Estado.
} 
exemplo, não é uma novidade para a América Latina. Segundo Miranda e Molina (2010), o continente sofreu diversas crises da divida ao longo da sua história, em larga medida associadas às políticas econômicas dos países desenvolvidos, a exemplo do que ocorreu na década de 1980 (ou a década perdida). A crise do petróleo do final dos anos de 1970 foi sentida fortemente nos preços da alimentação e nas condições de comércio local. Como resultado, houve na região grandes défices públicos que acabaram financiados através de divida externa. Os bancos comerciais estrangeiros, que tinham excesso de liquidez, encontraram na América Latina uma oportunidade para alocar esses recursos advindos da crise do petróleo. Por outro lado, os governos da América Latina, muitos dos quais à época em regime ditatorial, contraíram a divida negligentemente, esperando tirar proveito da diferença entre as taxas de juro locais e as estrangeiras.

Assim, entre 1970 e 1980, a divida externa da América Latina cresceu de 27 mil milhões para 231 mil milhões de dólares. As consequências econômicas e sociais da década perdida dos anos de 1980 são arrasadoras: o PIB per capita e os salários reais sofreram uma diminuição drástica; e consequentemente a qualidade de vida. A diferença entre ricos e pobres cresceu 50\% entre 1976 e 1983. Para evitar o incumprimento generalizado da divida, os EUA propuseram em 1989 o chamado plano Brady. O plano visava reestruturar dividas com bancos comerciais, com base numa conversão de empréstimos a preços de mercado e a extensão do período de reembolso. Em simultâneo foram tomadas medidas para estabilizar os problemas da balança de pagamentos, através de programas de ajuste estrutural do FMI e dos credores oficiais. No entanto, o Plano Brady tinha diversas falhas de base.

Depois do incumprimento da dívida soberana por parte do México, em 1982, que marcou o que muitos analistas viram como o início da crise da dívida moderna, os credores internacionais perderam a confiança na capacidade de reembolso das dividas de muitos países latinoamericanos. A maior parte dos bancos comerciais deixou de conceder empréstimos à América Latina e recusou refinanciar empréstimos já existentes, muitos dos quais eram a curto prazo e estavam a pagamento. Para evitar o pânico financeiro, os governos e empresas com problemas de liquidez viram-se forçados a renegociar os prazos de reembolso de empréstimos existentes e a contrair novos empréstimos para conseguirem fazer face ao serviço da enorme dívida existente. Os novos empréstimos foram feitos sob condições mais duras, que incluíam a adesão aos programas do FMI. Durante as décadas de 90 e 2000, praticamente todos os países da região 
contraíram algum tipo de empréstimo com o FMI - entre eles, a Argentina, o Belize, a Bolívia, o Brasil, o Chile, a Costa Rica, a República Dominicana, o Equador, El Salvador, a Guatemala, as Honduras, o México, a Nicarágua, o Panamá, o Paraguai, o Peru e o Uruguai. Esta onda de empréstimos do FMI na região vinha acompanhada de programas de reforma económica abrangentes, que tinham o objetivo de abrir as economias à competição estrangeira e permitir uma maior participação do sector privado no desenvolvimento. (MIRANDA \& MOLINA, 2010, s /n).

Reformas propostas não trouxeram um crescimento saudável. As taxas de inflação desceram na região e estabilizaram abaixo dos 10\%. Isto foi particularmente evidente em países como a Argentina, a Bolivia, o Brasil, a Nicarágua e o Peru. Posteriormente, a melhoria das finanças governamentais se traduziu num aumento dos gastos no setor público e na proteção social, que cresceu de 10\% para 13\% durante a década de 1990. Contudo, os benefícios de um desempenho macroeconómico mais forte foram reduzidos por uma tendência geral para adotar políticas fiscais e monetárias pró-cíclicas, que estavam na base do crescimento económico instável e das crises financeiras recorrentes na região. Desta forma, metade dos países da América Latina viveu crises financeiras durante os anos 1990. O modesto crescimento se refletiu em altos níveis de desemprego e pobreza e no crescimento do informalismo (MIRANDA; MOLINA, 2010).

Na Bolivia, um empréstimo do FMI que impôs a privatização do setor da água, levou a um aumento de $200 \%$ dos preços desse produto. Na Colômbia, o acordo do FMI aprovado em 2009 incluía políticas como a diminuição do setor público, sobretudo através da privatização e da diminuição dos gastos públicos. No Equador, o empréstimo assinado em 2000 exigia a contenção dos salários, a supressão dos subsídios, reformas no mercado do trabalho e no setor do petróleo e privatizações. Em todos os casos, houve vários protestos e greves. Estes são apenas alguns dos casos em que as imposições do FMI não só estavam mal concebidas, do ponto de vista econômico, como ultrapassaram as decisões dos governos eleitos na América Latina (MIRANDA; MOLINA, 2010). Mais de três décadas depois as crises da divida na região ainda estão presentes. No caso do Brasil, a face mais atual desse cenário, e do que acima caracterizamos como pós-democracia, se encontra na chamada PEC 55. 
A Proposta de Emenda Constitucional 55 foi a solução apresentada pelo então governo federal para aquilo que o discurso da austeridade fiscal entende como descontrole nas contas públicas e para que a iniciativa privada, nacional e internacional, retomasse a confiança no país e passasse a reinvestir na economia. Com tudo, a PEC não reduz gastos de imediato, mas limita o aumento dos gastos públicos (não poderão crescer acima da inflação acumulada do ano anterior) pelos próximos vinte anos, e como se trata de emenda constitucional essa política terá que ser adotada independente de quem forme os próximos governos, interferindo diretamente na atuação dos próximos mandatos. Como o Produto Interno Bruto (PIB) voltará a crescer em algum momento, com a PEC o Estado brasileiro necessariamente se contrairá. Para piorar, investimentos públicos essenciais, como em saúde, educação e assistência social, sofrerão o maior impacto, pois atualmente essas são as áreas que precisariam de mais investimentos. Sob esse novo regime, elas terão ainda menor possibilidade de serem incrementadas, afetando de forma desproporcional as populações mais vulneráveis. Especialistas apontaram os equivocos de tal proposta ${ }^{10}$ e a própria consultoria jurídica do Senado apontou sua inconstitucionalidade ${ }^{11}$, porém a maior parte dos deputados e senadores votaram a favor, em um cenário de diversas manifestações de funcionários públicos e ocupações de universidades por estudantes em todas as regiões pais. Então, a PEC foi sancionada no final de $2016^{12}$.

\section{Como a crise fiscal pode afetar toda uma geração de jovens}

O percurso teórico até aqui realizado almeja ampliar o horizonte de análise das políticas de austeridade. Normalmente o que temos são analises mais voltadas para o econômico, para a questão da confiança política e, se tratando dos efeitos desse contexto na vida da população jovem, basicamente aborda-se o desemprego. A exemplo do relatório "A anatomia da crise" de

\footnotetext{
10 A título de exemplo: http://www.gazetadopovo.com.br/vida-publica/especialistas-discutem-nosenado-pros-e-contras-da-pec-do-teto-veja-os-argumentos-8tnipud65rh8fmnsdwzc1yngf e

http://g1.globo.com/economia/noticia/2016/07/teto-de-gastos-deve-impactar-saude-e-educacaoavaliam-especialistas.html.

11 Ver detalhes no documento: https://www12.senado.leg.br/publicacoes/estudos-legislativos/tiposde-estudos/boletins-legislativos/bol53; ou na reportagem:

https://www.cartacapital.com.br/politica/consultoria-do-senado-aponta-inconstitucionalidade-dapec-dos-gastos.

12 http://www.cartacapital.com.br/revista/918/pec-241-a-moratoria-do-contrato-social.
} 
dezembro de 201313, abordando a resseção em Portugal, afirma que as consequências sociais têm sido severas quando se fala de desemprego, afetando particularmente os segmentos mais jovens da população ativa, a desproteção crescente dos desempregados e de outros setores mais vulneráveis da população, expulsão do país, sob a forma de emigração, de um número crescente de portugueses e o agravamento das desigualdades de rendimento. Entre o $2^{\circ}$ trimestre de 2010 e o $1^{\circ}$ trimestre de 2013 o número de jovens desempregados (15 aos 24 anos) aumentou 107\%. Em 2011 houve redução nas bolsas de estudos e o crescente risco de desqualificação profissional. Portugal possui um dos niveis mais altos de trabalho temporário da União Europeia, cerca de $22 \%$ para a população em geral - apenas abaixo da Polónia e da Eslovénia - e de 56\% para os jovens, em 2010. Tal situação acabou por gerar diversas manifestações, tais como o "12 de março", em 2011 , que correspondeu a um protesto massivo onde convergiram jovens afetados pelos empregos precários e outras fatias da população. Também se verificou que há uma queda mais acentuada na confiança política a partir de 2007, já sob o efeito da crise. Verificou-se esta perda de confiança na maioria dos grupos socioeconómicos, com uma maior expressão entre os jovens e os desempregados. O otimismo em relação ao futuro dentre os jovens entre 18 e 24 anos, aferido pela concordância em relação à questão "Estou otimista em relação ao futuro?”, foi um dos mais baixos em Portugal, perdendo apenas para a Grécia e a Eslováquia.

Na Espanha, o informativo "Crisis, desigualdade y pobreza" também de dezembro de $2013^{14}$, se atenta a natureza estrutural da crise atual e como ela está transformando a sociedade espanhola. Especificamente sobre a parcela jovem da população, destaca-se que a emigração espanhola se concentra principalmente entre os jovens formados e incapazes de encontrar trabalho no pais. O aumento da desigualdade e da pobreza está concentrada em lares com jovens chefes de família. Sobre a pobreza infantil na Catalunha: 23,7\% das crianças vivem abaixo do limiar da pobreza. Mas o maior drama que envolve este número é que essas crianças estão se tornando usuários crônicos de

13 Disponivel em: http://www.ces.uc.pt/ficheiros2/files/Relatorio_Anatomia_Crise_final_.pdf.

14 Disponivel em: http://www.pensamientocritico.org/Intermon0113.pdf. 
atividades e programas sociais e organizações de ajuda cada vez mais reduzidos. No caso de adolescentes e jovens isto torna-se realmente mais visivel, porque não ficam o dia todo em uma escola, e o corte de investimentos nessa área freia os projetos de pré-emprego. Aumentou-se o número dos chamados "ni-ni", não estudam nem trabalham, até 2013 esse número chegava a cerca de $22 \%$ de jovens na Catalunha. O "ni-ni” não são apenas um percentual, são adolescentes e jovens adultos que acabam cronicamente dependentes de um sistema de bem-estar. Um contexto assim, também gerou protestos, os mais conhecidos são referentes ao $15 \mathrm{M}-¡$ ¡Democracia real YA!

O Fórum Europeu da Juventude, de 2014, também promoveu estudo interessante, intitulado "Comment les jeunes se sont retrouves au milieu de la crise", sobre como a austeridade afeta países membros da União Europeia e da OCDE 15 , traz dados tais como: entre 2008 e 2012, a taxa de emprego dos jovens na UE diminuiu de 37,3\% para 32,8\%. O desemprego de longa duração aumentou drasticamente entre os jovens: atingindo $7,9 \%$ dessa população no final de 2012 (contra 4,9\% dos adultos). Em 2012, 15,9\% dos jovens com idade entre 15-29 anos estavam desempregados. 14,6 milhões de jovens em toda a UE não seguem os estudos ou formação e não trabalhar. Nessa área, por exemplo, na Grécia, em Portugal e na Irlanda, as despesas públicas com educação foram reduzidas em 14\% entre 2005 e 2010. Na Grécia, em 2012, o salário mínimo geral foi reduzido em $22 \%$, e o desemprego dos jovens atingiu $32 \%$. As estimativas indicam que o aumento do desemprego entre os jovens durante a crise aumentou a desigualdade de renda em 4 pontos entre todas as economias desenvolvidas - e até 8 pontos nos países da periferia da Europa, tais como Grécia, Irlanda, Itália, Portugal e Espanha, onde o mercado de trabalho para os jovens é bem mais deteriorado do que em outros países. Entre 2007 e 2011, os jovens com idades entre 18-25 anos sofreram as perdas de rendimento mais graves. Nos países da OCDE, o rendimento médio disponível de jovem caiu em termos reais, de $1 \%$ por ano (cerca de $11 \%$ ao ano na Grécia, 5\% na Espanha, 4\% na Estónia, e quase 2,5\% nos Países Baixos). Em vários

\footnotetext{
15 Disponivel em: http://www.youthforum.org/assets/2014/11/0365-14Youth-in-the-crisis-FR.pdf.
} 
desses países, mais de 50\% dos jovens entre 15-24 anos trabalhavam com contratos temporários, em 2011-2012. Na Eslovénia, eram 73\%.

No Brasil vale destacar:

No período de crescimento econômico entre 2004 e 2012, com evidentes efeitos positivos sobre o mercado de trabalho e sobre a estrutura social brasileira, ampliaram-se os espaços de inserção laboral dos jovens. Não somente os espaços foram ampliados, como a qualidade dos postos de trabalho oferecidos evoluiu positivamente, em razão da melhoria geral da estrutura de emprego e de renda. [...] Todavia, o crescimento de $0,1 \%$ do produto em 2014 e as estimativas para 2015 da maior retração da economia brasileira desde a recessão do início da década de 1990 vêm conduzindo o país para uma rápida reversão desse quadro de relações virtuosas. Por um lado, a degradação do mercado de trabalho. Dados da Pesquisa Mensal de Emprego para julho de 2015 indicam que, no conjunto das regiões metropolitanas, a taxa de desocupação subiu de $4,9 \%$ para $7,5 \%$ em 12 meses. Também indicam que o rendimento médio real caiu $2,4 \%$ e a massa de rendimentos dos ocupados, $3,5 \%$ no período (PME/IBGE). Por outro lado, os efeitos deletérios da estagnação econômica sobre a arrecadação pública e a desastrosa estratégia de "austeridade" adotada desde o início do ano têm provocado enormes constrangimentos em importantes políticas públicas. Como exemplo, o Ministério da Educação (MEC) anunciou que em 2015 a oferta de vagas no Pronatec cairá $60 \%$ e o número de novos contratos do Fies já caiu quase $50 \%$ no primeiro semestre do ano em comparação ao mesmo período de 2014. (SANTOS; GIMENEZ, 2015, p. 165).

Sem contar que esse contexto também serve para evidenciar ainda mais as intersecções de gênero e de raça no âmbito da desigualdade. Em 2013, no Brasil, quase metade das pessoas de 16 anos ou mais de cor preta ou parda ocupadas estavam em trabalhos informais: uma taxa de $48,7 \%$, contra $34,7 \%$ na população branca, diferença que pouco se alterou. Nesse mesmo ano, a taxa de jovens de 16 a 24 anos no trabalho informal era de 44,8\% e dos jovens de 25 a 29 era de $34,7 \% 16$.

Com isso, é possivel afirmar que os impactos gerais da crise económica no mercado de trabalho para jovens são bem conhecidos. O que propomos aqui é pensar em como a questão tributária frente a austeridade pode interferir em outras esferas da vida juvenil, e principalmente na própria desconfiguração desses sujeitos. Para fins didáticos, dividimos em tópicos esses aspectos que na concretude da vida estão inter-relacionados.

Um aspecto interessante para se pensar sobre a realidade tributária nacional são os recursos voltados a políticas de incentivo cultural. Segundo

\footnotetext{
16 http://exame.abril.com.br/economia/mulheres-pretos-jovens-e-idosos-lideram-trabalho-informal/.
} 
Tavares (2011), o tipo de política de fomento e incentivo à difusão da manifestação cultural mais comum que temos é o chamado "neocensitarismo", ou baseado no binômio habilitação-captação. De acordo com esse modelo, para se acessar os recursos públicos deve-se triunfar em dois expedientes seletivos: primeiramente, a produção cultural precisa obter a chancela da administração pública, atendendo, assim, a critérios prescritos em editais e se submeter a seleções e só assim o projeto é habilitado; em segundo lugar, a produção cultural deve obter apoio de algum agente de mercado, que seja contribuinte de tributos, para então poder acessar os recursos públicos destinados à cultura. Essa é a fase de captação, é o chamado "Incentivo Fiscal a Projetos Culturais" um mecanismo em que a União faculta às pessoas físicas ou jurídicas a opção pela aplicação de parcelas do imposto sobre a renda, a título de doações ou patrocínios, no apoio direto a projetos culturais, já "cadastrados" pelo poder público, ou em contribuições ao Fundo Nacional da Cultura (FNC). Ou seja, ao invés de aportar valores diretamente nos projetos culturais, o Estado concede exonerações tributárias e deixa ao sabor das vontades do contribuinte a autoridade para dispor acerca de para onde deve ir os recursos públicos que deixou de arrecadar. Entretanto, a produção artística e cultural encontra, historicamente, dois censores que se alternam em distintos modelos estatais: o paradigma liberal, onde o mercado censura a arte que não é ou não aceita se tornar mercadoria, como muitas obras de vanguarda oposicionista; e, em um marco autoritário, o Estado obstaculiza sobremaneira o direito fundamental à livre manifestação do pensamento e condiciona a difusão de obras.

Assim, as leis de incentivo à cultura baseadas no modelo da habilitação/captação instituem, como se nota, uma inédita dupla censura: uma onde as expressões devem se submeter ao crivo do Estado (habilitação); e outra onde elas devem se submeter ao mercado e aos "gostos" daqueles que se utilizam dos benefícios fiscais de tais leis. Com isso, além de uma tendência a burocratização, ocorre uma certa reificação da cultura.

O que não fica claro, segundo Tavares (2011), é como a simples justaposição de dois elementos de censura, sem exigir controle ou 
responsividade do outro, pode implicar em uma maior liberdade de expressão. Nesse modelo adotado, não há controles recíprocos entre Estado e mercado, mas apenas a sobreposição de ambos no controle de quem receberá os recursos para que possa levar a público sua expressão. Logo, conferir ao contribuinte esse tipo de direito implica subtrair da receita tributária a sua característica de recurso público. Isso oculta uma lógica censitária do poder estatal, ou seletiva, ideológica, como abordado anteriormente, onde os mais ricos teriam maior poder decisório sobre as fianças públicas.

Então, temos que as decisões referentes as produções culturais que receberão recursos públicos não costumam ser normativamente afetadas por nenhum foro participativo ou representativo da sociedade, mas sim ao juízo de empresas particulares. Ou seja, mineradoras, bancos, distribuidoras de combustiveis e seguradoras costumam decidir como serão gastos os recursos destinados a cultura. E mais, tais atores de mercado acabam por se beneficiarem duplamente, pois associam suas marcas às produções custeadas com dinheiro estatal como se fossem patrocinadoras (TAVARES, 2011).

Isso está diretamente ligado ao consumo de massa e a formulação das preferencias individuais. Entretanto, o mais preocupante é que uma lógica de incentivo com bases tributarias, nos moldes apresentados, tende a impedir, por exemplo, expressões culturais subalternas, tais como a LGBT $^{17}$, pois entrega ao mercado o custeio da cultura. Por sua vez, considerando que o mercado possui uma esfera político-ideológica, o questionamento que surge é: qual tipo de cultura o mercado irá patrocinar?

Para entender como essa lógica interfere no próprio sujeito, Brown (2015) aborda a racionalidade neoliberal como um risco ao projeto ideal, imaginário e político da democracia e como algo que inverte liberdade em sacrificio. Desde a sua emergência no final do século XVIII até o presente, a democracia liberal europeia sempre foi saturada com poderes e valores capitalistas. De modo geral, por meio de suas abstrações politicas e jurídicas, ela assegurou o poder e os privilégios dos socialmente dominantes, consagrando não só a propriedade privada e os direitos do capital, mas o

17 Ver: http://www.huffpostbrasil.com/thiago-coacci/a-pec-55-e-as-politicas-lgbt_a_21699753/. 
racialismo e uma divisão sexual do trabalho subordinada normativamente. Em conjunto, esses preceitos asseguram uma vida social, cultural e econômica desigual e desprovida de liberdade ao repudiar sua intersecção com as divisões do trabalho e das estratificações de classes e sua mobilização de normas de personalidade fortemente influenciadas por raça, gênero e cultura.

Além de abrigar um ideal em excesso, a divisão da democracia liberal entre os princípios formais e a existência concreta, fornece o cenário da contradição que os movimentos sociais de todo tipo exploraram já a mais de três séculos. Essa promessa de realização plena dos princípios democráticos são o que a racionalidade política neoliberal compromete com a eliminação da própria ideia de "demos", com a sua derrota do homo politicus pelo homo economicus, com a sua hostilidade à política, com sua "economização" dos termos da democracia liberal e com seu deslocamento dos valores legais democráticos.

Segundo Brown (2015), a "economização" substitui um léxico político por um léxico de mercado. A governança substitui um léxico político por um léxico de gestão. A combinação transforma a promessa democrática de uma regra compartilhada na promessa de gestão empresarial e de portfólio a nível individual e coletivo. No mundo euro-atlântico de hoje, parece haver uma boa dose de descontentamento, ou ao menos de desconforto, devido a neoliberalização da vida cotidiana. Porém, essa infelicidade cotidiana tende a se concentrar na geração de desigualdades extremas do neoliberalismo, nos seus niveis invasivos ou grosseiros de mercantilização ou no seu desmantelamento de bens públicos e comercialização da vida pública, assim como do espaço público.

A autora sugere que a democracia não promete nos salvar da dominação, nem pelos imperativos diretos, nem pelos poderes do capitalismo. A democracia é uma forma vazia que pode ser preenchida com uma variedade de conteúdos ruins e instrumentalizada para propósitos que vão da xenofobia nacionalista ao colonialismo racial, da hegemonia heterossexual à hegemonia capitalista; mas também pode ser mobilizada dentro dos mesmos regimes para contrariar esses propósitos. Só que se a democracia representa a ideia de que o povo, ao invés de outra coisa, decidirá os fundamentos e as coordenadas de 
sua existência comum, a economia desse princípio é o que pode finalmente matá-la. Como essa racionalidade elimina os últimos traços clássicos de cidadania republicana, formulados como engajamento com o interesse público, ela retém e transforma a ideia de sacrificio do cidadão.

Enquanto, na transição da democracia liberal para a democracia neoliberal, a virtude cidadã é retrabalhada como empreendedorismo responsabilizado e auto investimento, também é retrabalhada na era da austeridade como o "sacrificio compartilhado" cotidianamente solicitado pelos líderes de Estados e chefes de negócios. Este "encurtamento" da cidadania ativa e a expansão do sacrifício do cidadão são facilitados pela suplantação neoliberal dos valores políticos democráticos e do discurso com a governança. Nesse contexto, a terceirização, as reduções de salários e beneficios, juntamente com a redução dos serviços públicos, todos se apresentam como decisões de negócios, não políticas. E onde as medidas de austeridade são mais severas, como na chamada "periferia europeia", isso significa aceitar altas e persistentes taxas de desemprego combinadas com cortes em proteções e serviços sociais, em uma noção de que os cidadãos leais devem "compartilhar o sacrificio" na aceitação da austeridade (BROWN, 2015).

Assim, enquanto o neoliberalismo promete, formalmente, libertar o cidadão do Estado, da política e até mesmo da preocupação com o social, na prática, ele integra o Estado e a cidadania no serviço da economia e moralmente funde a autoconfiança com a prontidão para ser sacrificada. Com isso, onde os sectores públicos ostensivamente inchados, sujeitos indulgentes ou nações são alvo de cortes ou reestruturação, um discurso de culpa circula. Desse modo, são tomadas medidas para punir ou disciplinar povos, regiões ou práticas "preguiçosas" (como no lema do atual governo federal brasileiro que afirma a necessidade de se trabalhar arduamente para superar a crise). Deixa-se de lado o caráter estrutural das crises fiscais

Então, pergunta-se Brown (2015), por que o sacrifício compartilhado hoje é a língua dos negócios e dos governos, circulando entre firmas grandes e pequenas e acompanhando a reestruturação fiscal ou os resgates na União Europeia, estados, municípios ou certos setores econômicos e públicos? Que 
órbita de significado abriga o chamado para o sacrificio compartilhado na politica de austeridade neoliberal?

As we are enjoined to sacrifice to the economy as the supreme power and to sacrifice for "recovery" or balanced budgets, neoliberal austerity politics draws on both the religious and secular, political meanings of the term. We appear to be in the orbit of the second, secular meaning insofar as "sharing" is called for, rather than assumed, the call itself is issued in a moral-political idiom, and the call implies overcoming self-interest for the good of the team. Yet the devastation of human well-being entailed in slashed jobs, pay, benefits, and services brings no immediate returns to those who sacrifice or are sacrificed. Rather, the putative aim is restoration of economic and state fiscal "health", a return from the brink of bankruptcy, currency collapse, debt default, or credit downgrade. Moreover, the addressee of sacrifice is not the nation, not the demos, but the spectacularly imbricated state and economy on which all life depends, but which also command destruction and deprivation. In the 2008 subprime mortgage crisis, for example, billion taxpayer dollars and over five million homeowners were fed to banks "too big to fail". Thus we are returned to the religious valence of sacrifice. In shared sacrifice for economic restoration, we sacrifice "to", rather than "for," and make an offering to a supreme power on which we are radically dependent, but that owes us nothing. We are called to offer life to propitiate and regenerate its life-giving capacities... but without any guarantee that the benefits of this sacrifice will redound to us (BROWN, 2015, p. 216) ${ }^{18}$.

Assim, em vez de preservar a comunidade através do sacrificio de uma vítima, toda a comunidade é chamada a sacrificar-se para salvar elementos particulares dentro dela. Por exemplo, a raiva apropriadamente dirigida aos bancos de investimento é redirecionada para um apelo ao sacrifício compartilhado realizado por suas vítimas (BROWN, 2015). Daí a autora voltar a questionar: qual é a desarmonia ou o tecido social rasgado que está em jogo no chamado ao sacrificio dentro dos regimes neoliberais contemporâneos? É apenas fiscal e econômico? Trata-se apenas de divida, de gastos ou mesmo de

\footnotetext{
18 Em tradução livre: "Como somos obrigados a sacrificar a economia como o poder supremo e se sacrificar pela "recuperação" ou pelos orçamentos equilibrados, a política de austeridade neoliberal baseia-se nos significados politicos e religiosos seculares do termo. Parecemos estar na órbita do segundo significado secular na medida em que o "compartilhamento" é chamado, em vez de assumir, e onde a chamada em si é emitida em um idioma moral-politico, tal chamado implica superar o interesse próprio pelo bem do time. No entanto, a devastação do bem-estar humano decorrente de empregos, salários, benefícios e serviços reduzidos não traz retornos imediatos aos que sacrificam ou são sacrificados. Em vez disso, o suposto objetivo é a restauração da "saúde" econômica e estatal, um retorno da maré da falência, colapso cambial, inadimplência ou crédito inferior. Além disso, o destinatário do sacrificio não é a nação, não é o demos, mas o estado e a economia espetacularmente imbricados de que depende toda a vida, mas que também exigem destruição e privação. Na crise das hipotecas de 2008 , por exemplo, 700 bilhões de dólares dos contribuintes e mais de cinco milhões de proprietários foram alimentados aos bancos "muito grandes para falhar". Assim, somos devolvidos à valência religiosa do sacrifício. Em sacrificios compartilhados pela restauração econômica, sacrificamos "a", em vez de "por", e oferecemos a um poder supremo sobre o qual somos radicalmente dependentes, mas ele não nos deve nada. Estamos chamados a oferecer vida para propiciar e regenerar suas capacidades vitais... Mas sem qualquer garantia de que os beneficios deste sacrificio redundem para nós."
} 
instituições financeiras indevidamente regulamentadas? Ela conclui que, talvez, também esteja em jogo uma crise de valores, uma crise na identidade, de política, até mesmo uma crise da democracia.

O cidadão neoliberal devidamente interpelado não reivindica a proteção contra as "bolhas estouradas" do capitalismo, as recessões que afetam os empregos, os abalos de crédito, o colapso do mercado imobiliário, a terceirização ou, o que a autora chama de "a descoberta de prazer e lucro apostando contra si mesmo ou apostando em catástrofe". Este cidadão também aceita a intensificação das desigualdades, este cidadão liberta o Estado, a lei e a economia da responsabilidade da sua própria condição e está pronto quando chamado a se sacrificar pela causa do crescimento econômico, posicionamento competitivo e restrições fiscais. Essa perda de convicção sobre a capacidade humana de criar e dirigir a sua existência ou mesmo de assegurar seu futuro é o sentido mais profundo e devastador em que a modernidade está "acabada". É a perversa teologia do mercado do neoliberalismo (BROWN, 2015).

Ressalta-se, ainda, que a racionalidade neoliberal não germinou esse desespero civilizatório, porém sua figuração do humano, seu princípio de realidade e sua cosmovisão - "não há alternativa" - consagra, aprofunda e naturaliza sem reconhecer esse desespero. Ao deixar que os mercados decidam o nosso presente e o futuro, o neoliberalismo abandona totalmente o projeto de domínio individual ou coletivo da existência. Assim, a solução desse sistema para os problemas é sempre mais mercados, novas tecnologias, novas formas de monetizar, etc. Qualquer coisa, menos a tomada de decisão humana colaborativa e contestatória, controle sobre as condições de existência, planejamento para o futuro; qualquer coisa menos construções deliberadas da existência através de discussão democrática, lei, política. Qualquer coisa, exceto o conhecimento humano e a ação classicamente associados ao homo politicus.

Brown (2015), conclui então, que na esteira perpétua de uma economia capitalista que não pode cessar sem colapso é agora a esteira em que cada ser e atividade é colocada, e os horizontes de todos os outros significados e propósitos encolhem em conformidade a isso. Este é o ponto de virada 
civilizacional que marca a racionalidade neoliberal, seu pós-modernismo e anti-humanismo profundo, uma condição sentida e vivida de impotência humana, desconhecimento, fracasso e irresponsabilidade.

Tal linha de raciocínio pode ser complementada com a interpelação do sujeito com o indivíduo trabalhada por Jodi Dean (2014), já que esta aborda isso por meio da ideologia, e aqui trabalhamos, aos moldes de Blyth (2013), a austeridade como uma forma de ideologia. Assim, a autora afirma que a presunção de que os agentes são individuos formata a alternativa de autonomia ou subjugação como oposição entre individual e coletivo e que a ligação entre individualidade e subjetividade politica não é nem necessária e nem natural. E sim um efeito contingente ao conjunto de processos que convergem na modernidade burguesa.

Para Dean (2014), assim como a mercadoria é uma forma de valor, o indivíduo também é uma forma de subjetividade. É uma forma que impede a subjetividade politica coletiva, separando-a e contendo-a dentro de corpos e mentes individualizados, concebido como o proprietário de sua própria pessoa ou capacidades, não devendo nada à sociedade. Compreendem o indivíduo não primariamente como uma parte ou membro, nem como fundamental e irrevogavelmente dependente das relações com os outros humanos e não humanos. Pelo contrário, o indivíduo é, em essência, aquele que possui a si mesmo e suas capacidades. Reflexivamente, as capacidades são separadas das outras, bem como separadas de um eu, que encerra essas capacidades dentro de sua pessoa. Em vez de reprodução para o bem comum, treinamento, moral ou técnico, é trabalho sobre e para o eu. Isso emerge historicamente como um mecanismo ideológico para a "des-subjetivação" dos coletivos e para a criação de escravos para o mercado.

É a ideologia burguesa que trata de condições coletivas e sociais, embutidas em sistemas de exploração, como se fossem relações próprias de um indivíduo, como se os estados surgissem através do consentimento individual, como se a política fosse uma questão de escolha individual e como se os desejos e capacidades residissem em uma forma individual. Ao contrário, assim como a experiência coletiva de antagonismo - a "substância social" - 
subjuga o que Marx chama de "objetividade fantasmagórica"19 da mercadoria, também subjaz à subjetividade fantasmagórica do indivíduo. Quando o sujeito é interpelado como um indivíduo, os pontos fortes de muitos se tornam os atributos imaginários de um. O indivíduo aparece como o lócus de uma capacidade de inovação e interrupção que é apenas um efeito das coletividades. As práticas generativas que as pessoas empreendem em comum são despojadas de suas sensibilidades compartilhadas, reduzidas às atividades de eu(s) separados. Se a ideologia é a relação imaginária dos indivíduos com suas condições reais de existência, como afirma Althusser (1974), essas condições serão representadas como questões individuais de preferência e escolhas individuais, crenças e circunstâncias. As contradições constitutivas das relações capitalistas existirão e aparecerão. A coletividade, por sua vez, será calculada de forma derivada, à sombra do indivíduo, de forma que a subjetividade que ela evidencia não apareça como efeito de um sujeito. A unidade aparece como vício. A multidão se torna inconsciente outra vez, na operação continuada do cerco efetuado pela forma individual. Ou seja, o indivíduo é impossibilitado de se ligar a coletividade (DEAN, 2014).

\section{Conclusão}

Para fins de conclusão e considerando que este trabalho se trata de um ensaio teórico, pode-se dizer que a atual crise fiscal e as suas politicas de austeridade, possuem uma origem estrutural, e não apenas de gestão, na conformação dos estados modernos, devido em grande parte as contradições insuperáveis entre democracia e capitalismo como apresentadas por Wood (2011). Isso afeta diretamente a formação e a dinâmica dos sujeitos em sociedade. Buscou-se deixar claro seu caráter ideológico, de classe, e que a forma com que um Estado conforma a sua tributação deve ser uma decisão de cunho democrático, a exemplo de propostas como: leis que assegurem maior transparência da Administração Pública, com acesso facilitado ao

\footnotetext{
19 Se refere a discussão que Marx (2013) faz no livro 1 do Capital, abordando a objetividade do trabalho e a formação do valor: "[...]Ao transformar o dinheiro em mercadorias, que servem de matérias para a criação de novos produtos ou como fatores do processo de trabalho, ao incorporar força viva de trabalho à sua objetividade morta, o capitalista transforma o valor - o trabalho passado, objetivado, morto - em capital, em valor que se autovaloriza, um monstro vivo que se põe a "trabalhar" como se seu corpo estivesse possuído de amor"(p. 349).
} 
cidadão, os quais devem ser conferidos direitos de ação contra o uso ilegal ou ilegítimo dos recursos orçamentários, assim como poderes jurídicos para atuar na fiscalização da aplicação dos recursos públicos, de forma que o envolvimento com as politicas tributárias e fiscais seja dinamizado20. Porém, com a erosão na base de arrecadação dos Estados nacionais ocorrida nos últimos anos, vem-se transformando cada vez mais explicitamente essa lógica.

Com a adoção de medidas de austeridades, tais como a PEC 55 no Brasil, os Estados passam a ser governados por "gente morta", no sentido de governantes com as mãos atadas, com pouca margem de manobra para executar suas políticas, pois o dinheiro arrecadado pelos impostos já chega com um destino específico, independente do governo em exercício ser alinhado à direita ou à esquerda, o pagamento da divida pública. O orçamento acaba não sendo submetido de fato a uma discussão democrática, cidadã. Vivemos agora em uma "pós-democracia".

Isso, é claro, terá reflexos na vida concreta dos cidadãos, na práxis social. O mais imediato deles a ser identificado são em relação aos cortes nos investimentos em demandas sociais como saúde, habitação, educação, tudo isso fica potencialmente prejudicado. As questões referentes ao mundo do trabalho também passarão a ser bastante discutidas nessa "era de austeridade", principalmente no que tange a sua tendência de flexibilização e uma exploração cada vez maior dos trabalhadores. Podem ser encontrados diversos estudos também sobre as guerras fiscais entre estados. Mas há uma lacuna quando se trata dos reflexos dessas politicas para a população jovem que vá além de questões trabalhistas, quando se trata da própria conformação dessas crianças e adolescentes.

Tentando preencher um pouco essa lacuna, buscamos apresentar essas transformações em dois eixos: o primeiro cultural, que afetara em grande medida as escolhas estéticas e a ideia de "gosto" de crianças e adolescentes. Pois o mecanismo de mudança individual ao longo do desenvolvimento desse sujeito tem origem na sociedade e na cultura (VYGOTSKY, 1991). Silva (2008), nos ajuda a entender melhor como essas mudanças no contexto

20 http://www.ambito-juridico.com.br/site/index.php?n_link=revista_artigos_leitura\&artigo_id=10520. 
socioeconômico afetam questões referentes a cultura, incidindo sobre o próprio sujeito dessa população jovem. Segundo ele, a cultura é prática de significação e como tal, assume papel não apenas constituidor, mas também determinante, superestrutural. Ou seja, a cultura é atividade, é ação, é experiência, relações, é sempre trabalho sobre alguma coisa. Assim, ela dever ser vista menos como um produto e mais como produção, criação, trabalho. Essas contradições sociais, advindas do desenvolvimento do sistema capitalista, podem ser apreendidas pelos individuos, já que esta é meio de formação e produto da relação entre estes, cultura e natureza. E é nos jovens que essas tensões e contradições, entre indivíduo e sociedade, estão mais patentes e se expressam mais espontaneamente. Daí Batista (2008) concluir que, diante disso não se pode perder de vista a dinâmica social que engendra a formação do sujeito. O que, no caso da formação dos jovens contemporâneos se refere a uma formação assentada sobre os moldes da racionalidade tecnológica, apelos consumistas, relações cada vez mais instrumentais e superficiais, indiferença social, fragilização individual, etc.

E em segundo, falamos do caráter estrutural da interpelação dos sujeitos e de como o neoliberalismo promoveu transformações nesses sujeitos que impedem a legitimidade democrática, pois quando o sujeito é interpelado como um indivíduo, os pontos fortes de muitos se tornam os atributos imaginários de um, as práticas generativas que as pessoas empreendem em comum são despojadas de suas sensibilidades compartilhadas, reduzidas às atividades de eu(s) separados. Ou seja, temos um indivíduo impossibilitado de se ligar a coletividade. Em tal contexto, isso pode se refletir, por exemplo, em formas de participação e não participação (aos moldes do "ativismo negativo") 21 .

\section{Bibliografia}

ALTHUSSER, Louis. Ideologia e aparelhos ideológicos do Estado. Lisboa: Editoria Presença / Martins Fontes, 1974.

\footnotetext{
21 A ideia seria que essas conformações têm muito mais influência do que, por exemplo, escola e família, como defende Mario Fuks em seu artigo "Atitudes, cognição e participação política: padrões de influência dos ambientes de socialização sobre o perfil politico dos jovens".
} 
BATISTA, Maria Isabel F. C. S. A formação do individuo no capitalismo tardio: um estudo sobre a juventude contemporânea. São Paulo. Tese de Doutorado. Programa de Psicologia Social, Pontificia Universidade Católica de São Paulo, 2008.

BLYTH, Mark. Austerity: the history of a dangerous idea. Oxford: Oxford University Press, 2013.

BROWN, Wendy. Losing Bare Democracy and the inversion of Freedom into sacrifice. In: BROWN, Wendy. Undoing the demos: neoliberalism's stealth revolution. Cambridge: MIT Press, 2015.

CROUCH, Colin. Post-Democracy. Cambridge: Polity, 2004.

DEAN, Jodi. Enclosing the Subject. Political Theory, v. 44, n. 3, 2014.

KALECKI, Michal. Political Aspects of full employment. The Political Quarterly, v. 14, n. 4, 1943.

MARX, Karl. O Capital: crítica da economia política - Livro 1, O processo de produção do capital. São Paulo: Boitempo Editorial, 2013.

MIRANDA, Patricia; MOLINA, Nuria. Debt Crises and Austerity Policies in Latin America: Lessons for Europe. The Citizen, n. 4, September 2011. Tradução disponivel em: http://auditoriacidada.info/article/crises-dad\%C3\%ADvida-e-pol\%C3\%ADticas-de-austeridade-na-am\%C3\%A9ricalatina-1i\%C3\%A7\%C3\%B5es-para-europa. Acesso em: 10/02/2017.

OFFE, Claus; RONGE, Volker. Dominação de classe e sistema político. Sobre a seletividade das instituições politicas. In: OFFE, Claus. Problemas estruturais do Estado capitalista. Rio de Janeiro: Tempo Brasileiro, 1984, p. 122-139.

SANTOS, Anselmo Luis dos; GIMENEZ, Denis Maracci. Inserção dos jovens no mercado de trabalho. Revista Estudos Avançados, São Paulo, v. 29, n. 85, 2015.

SCHAFER, Armin; STREECK, Wolfgang. Introduction: politics in the age of austerity. In: SCHAFER, Armin; STREECK, Wolfgang (eds). Politics in the Age of Austerity. Cambridge: Polity, 2013.

SCHUMPETER, Joseph A. The crisis of the Tax State. In: SWEDBERG, Richard (org.). Joseph Schumpeter: the economics and sociology of capitalismo. Princeton: Princeton University Press, 1991.

SILVA, Tomaz Tadeu da. Cultura e subjetividade na juventude. In: Cadernos CEnPeC, Núcleo de Pesquisa do Programa Jovens Urbanos, n. 5, 2008. Disponivel em: http:/ / cadernos.cenpec.org.br/cadernos/index.php/cadernos/article/view/ 80/95. Acesso em: 28/04/2017. 
STEINMO, Sven. Taxation and Democracy. London: Yele University Press, 1993.

STREECK, Wolfgang. As crises do capitalismo democrático. Tradução de Alexandre Morales. Novos Estudos - CEBRAP, São Paulo, n. 92, 2012.

TAVARES, Francisco Mata Machado. As politicas públicas de promoção do direito humano à difusão da manifestação cultural no Brasil: uma apreciação teórica dos principais modelos de incentivo à cultura. Revista Políticas Públicas, São Luís, v. 15, n. 2, 2011.

TAVARES, Francisco Mata Machado. A dimensão politica da crise fiscal dos estados contemporâneos: um estudo sobre o potencial da democracia deliberativa para a coibição das concorrências tributarias danosas. Belo Horizonte. Dissertação de mestrado, Programa de Pós-Graduação em Ciência Politica, Universidade Federal de Minas Gerais, 2008.

VYGOTSKI, L. S. A formação social da mente. $4^{a}$ ed., São Paulo: Martins Fontes Editora Ltda, 1991.

WOOD, Ellen Meiksins. Democracia contra Capitalismo: a renovação do materialismo histórico. São Paulo: Boitempo, 2011.

Transitions. In: WOOD, Ellen Meiksins. Liberty and Property: a social history of western political thought from renaissance to enlightenment. London: Verso, 2012. 